\title{
Projeto de Assentamento Rural: o parcelamento e as dinâmicas ambientais no Zumbi dos Palmares - laras/SP
}

\author{
CARAFFA, Marina ${ }^{1}$ \\ ${ }^{1}$ Faculdade de Arquitetura e Urbanismo da Universidade de São Paulo FAU USP, São Paulo, Brasil. mcaraffa@gmail.com
}

\begin{abstract}
Resumo
Apresentando os resultados finais da dissertação de mestrado, intitulada Projeto de Assentamento Rural: um estudo do ambiente construído no Zumbi dos Palmares, este artigo busca dar continuidade à discussão a respeito do projeto de assentamento como instrumento de materialização da política de reforma agrária. Considerando-se que as diretrizes de projetos não são cumpridas em sua totalidade, e que o assentamento estudado segue agregando glebas no seu perímetro, toma-se a condicionante ambiental como elemento de análise para se identificar os impactos da ocupação ocorrida nos últimos 17 anos. A pesquisa acerca da resultante do ambiente construído no assentamento indicou que o projeto de ordenamento dos lotes não considera a condição ambiental da área, e que não foram usados critérios técnicos para as definições do ordenamento. A consequência dessa condição é um ambiente construído frágil e precário, além de um ponto crítico no cotidiano das famílias. $\mathrm{O}$ objetivo desta continuidade foi, então, reconhecer as transformações ambientais ocorridas durante as etapas de parcelamento e sua relação com o projeto.
\end{abstract}

Palavras-Chave: Projeto, Assentamento Rural, Meio Ambiente

\begin{abstract}
Presenting the final results of the dissertation, titled Rural Settlement Project: an environmental study built in Zumbi dos Palmares, this paper aims to continue the discussion of the settlement project as a materialization instrument of agrarian reform policy. Considering that the draft guidelines have not been delivered at all, and that the settlement studied has followed adding plots within their boundaries, the environmental condition becomes an analytical element to identify the impacts of occupation that have occurred in the last 17 years. The research on the result of the built environment in this settlement pointed out that the planning project of the lots did not consider the environmental condition of the area and any technical criteria have been used for the system settings. The consequence of this condition is a fragile and precarious built environment beyond a critical point in the household routine. The purpose of this continuity was recognizing the environmental changes that occurred during the installment steps and their relation to the project as well.
\end{abstract}

Key-Words: Design, Rural Settlement, 


\section{Introdução}

A aproximação com 0 universo dos assentamentos rurais revelou que os aspectos sociais e ambientais são os mais frágeis. Quando se estuda o conteúdo que engloba o processo de criação e o resultado do ambiente construído, nota-se que não há considerações sobre as condicionantes ambientais existentes, nem, tampouco sobre a dinâmica entre produção e meio ambiente. Para arquitetos e urbanistas, o projeto de um assentamento humano, independentemente da escala considera para definição do partido: as condicionantes de inserção regional (localização, acessos), dinâmica ambiental do local de implantação, além de considerar, para a definição do programa de necessidades 0 perfil social das famílias, para então, definir traçado e uso do solo. Nesse sentido, independentemente do fato de ser urbano ou rural o projeto de parcelamento, para um assentamento humano, deveria considerar não só as atividades produtivas e a organização social das famílias, mas principalmente as dinâmicas ambientais que emolduram as especificidades da vida nos assentamentos rurais de reforma agrária.

A legislação que cria e regulamenta a implantação dos projetos de assentamento de reforma agrária tem sido objeto das ações governamentais mais do que a criação de novas implantações. Nelas, estão previstas atividades e etapas que promovam a participação das famílias, e que o meio ambiente seja incluído no projeto de parcelamento, mas também no cotidiano. No entanto, a fragilidade expressa no ambiente construído apresenta um quadro diferente daquele proposto no desenho das políticas e dos programas que apoiam as famílias assentadas. Embora o objetivo do projeto de assentamento seja a promoção da distribuição de terras, tendo em vista a diminuição da pobreza, o que se observa reflete então certa falta de capacidade técnica para operar as políticas disponíveis, e talvez 0 descolamento entre o que é previsto na Lei e o que se pratica de fato.

Não é estranho que esse tipo de ordenamento social tenha sido raro objeto de estudo para os arquitetos e urbanistas, uma vez que, historicamente, os temas relacionados à reforma agrária e ao meio rural foram mantidos no âmbito das ciências agrárias e econômicas, enquanto os arquitetos e urbanistas debruçaram-se sobre 0 contexto e complexidades do desenvolvimento urbano. Assim, a definição do tamanho do lote tem sido objeto de discussão para os técnicos das áreas agronômicas, associados aos economistas, na definição de área mínima para o lote em função da produtividade da terra/família. Não há, entretanto, uma preocupação com a resultante do ordenamento dos lotes, das áreas comuns e institucionais, do traçado das vias, que são definidos, na maioria das vezes, no gabinete técnico. Tampouco há, no quadro de técnicos designados a elaboração dos projetos, assistentes sociais que aproximem as famílias desse processo, nem arquitetos e urbanistas que possam, por suas atribuições, relacionar o objetivo do projeto de parcelamento, a dinâmica ambiental da área e o modo de vida das famílias.

Assim como as diretrizes e as orientações para a elaboração do projeto de assentamento rural não são cumpridas, as diretrizes de proteção e preservação ambiental não se fazem cumprir nos assentamentos rurais paulistas. Dando continuidade à pesquisa que resultou na dissertação de mestrado Projeto de Assentamento Rural: um estudo do ambiente construído no Zumbi dos Palmares, este trabalho busca analisar a evolução das etapas de parcelamento, agora, sob o ponto de vista ambiental: uma leitura dessas etapas, feita a partir de imagens de satélite. $O$ objetivo desta continuidade foi reconhecer as transformações ambientais ocorridas após a ocupação, e colaborar com a reflexão sobre o parcelamento do projeto de assentamento rural a partir de suas características ambientais.

\section{Projetos de Assentamento Rural: tipologias}

O projeto de assentamento é previsto em como um conjunto de unidades agrícolas independentes entre si, implantadas num imóvel 
rural que pertencia anteriormente a um único proprietário. É destinado a ser lugar de moradia e trabalho das famílias beneficiárias do Programa Nacional de Reforma Agrária, que implica especificidades complexas no cotidiano, que abarcam desde aspectos do projeto de parcelamento dos lotes, traçado de vias, definição da tipologia de uso e ocupação do solo permeado por dinâmicas burocráticas que levam um tempo diferente daquele experimentado no dia-a-dia.

[...] pensar na ideia de materialização é pensar na repercussão que 0 assentamento proporciona. Sua efetivação repercute tanto do ponto de vista material como do ponto de vista social e simbólico. O assentamento é um espaço remodelado, povoado ou repovoado, recortado e dividido. São construídas casas e estradas, realizamse lavouras e criações, realizam-se também encontros e reuniões que resultam em formação política, ocorrem manifestações, reivindicações, conflitos internos e externos, com isso toda uma dimensão política e cultural brota do projeto de assentamento. Concomitantemente, todo esse processo significa uma série de impactos sobre a família produtora dessa nova situação (MITIDIERO, 2012, p.12).

As implantações representam a materialização da política de reforma agrária. Em São Paulo a maioria é de origem federal - Projeto de Assentamento Rural (PA) e a partir de 2010 observam-se implantações do tipo Projeto de Desenvolvimento Sustentável (PDS), além das implantações resultantes de ações do órgão estadual que colabora com 0 acesso às políticas públicas de reforma agrária - Projeto Estadual (PE). Como órgão operador da política nacional, o Instituto Nacional de Colonização e Reforma Agrária - INCRA reconhece os projetos estaduais do Instituto de Terras de São Paulo.

Os dados do INCRA de São Paulo (SR08) indicam um total de 230 assentamentos dos tipos PA | PDS | PE, dos quais a maioria tem mais de dez anos, ou seja, estariam na metade do amadurecimento previsto para emancipação, e os outros com menos de dez anos. Nesses últimos vinte anos de implantações muitas foram as evoluções, principalmente no que diz respeito à disponibilização de políticas públicas específicas para essa condição social, mas não se observa maior mobilização não só para o estudo, mas a prática da etapa de desenho, entendido como etapa de projeto a definição da forma de ocupação e uso do solo. A figura a seguir ilustra as ocupações no Estado de São Paulo por tipo de projeto.

Figura 1: Assentamentos rurais em SP - 1985 - 2012

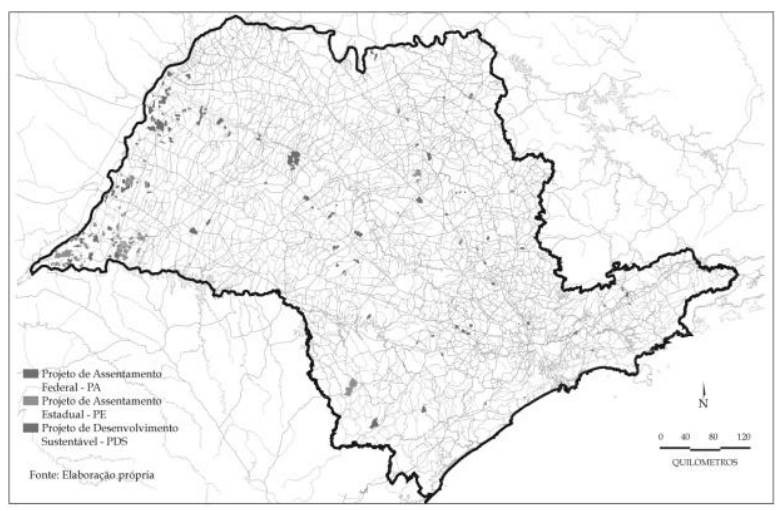

Além de ser um evento altamente político como afirma Mitidiero (2012), a materialização do assentamento implica repercussão importante na paisagem que se transforma, mas principalmente no cotidiano das famílias que ali irão viver. Diferentemente daquilo que está previsto nas instruções normativas técnicas para a implantação e desenvolvimento de projetos de assentamento rural poucas são as etapas cumpridas de fato, ao que parece a ausência desses procedimentos colabora com a fragilidade ambiental que se observa nas ocupações.

Pode ser reconhecida também uma tipologia de parcelamento determinada pela interação com as famílias beneficiárias que optam por formas diferenciadas de organização o que reflete diretamente na definição do uso do solo, ordenamento dos lotes e consequentemente no modo de vida das famílias. Após a criação de um projeto de assentamento deveria ser feito o Plano de Desenvolvimento do Assentamento (PDA) no qual seria definido o parcelamento em função do modo de vida e produção das famílias, no entanto, o que se observa é que a 
maioria das implantações paulistas com mais de dez anos - independentemente se federal ou estadual - resultam parcelamentos do tipo xadrez, indicando a reprodução de um padrão para esse plano, ao menos no que diz respeito a definição do uso do solo. No Estado paulista foram identificados ao menos três formas de parcelamento: a agrovila, o xadrez e a roda de carroça. Sendo que o xadrez representa 96,94 $\%$ das implantações, a agrovila $1,83 \%$ e o tipo roda de carroça $1,22 \%$. Esse resultado poderia ser explicado em função do tempo de existência dos assentamentos e das dificuldades operacionais.

As formas diferenciadas de parcelamento resultam de experiências isoladas resultantes da colaboração entre a equipe técnica e operacional do órgão público e as famílias mobilizadas e dispostas ou a formas de produção coletiva ou ambientalmente diferenciada. Essas formas de parcelamento diferenciadas se caracterizam pelo parcelamento de lotes individuais menores para moradia e a produção é coletiva.

\section{Assentamento: Projeto de Desenvolvimento Sustentável}

Em 1975 em São Paulo e no Rio de Janeiro foi colocado em prática o Licenciamento Ambiental, que em 1981 seria estabelecido nacionalmente por meio da Política Nacional de Meio Ambiente - lei Federal 6.983. Na Constituição Federal esteve presente no capítulo referente à Proteção do Meio Ambiente, artigo 225. Em 1996 são registrados os primeiros projetos ambientalmente diferenciados - chamados Projetos Agroextrativistas, destinado a população tradicional extrativista da Amazônia. No ano seguinte a resolução CONAMA 237 dispõe sobre a revisão e complementação dos procedimentos e critérios utilizados para 0 licenciamento ambiental, incluindo entre as atividades ou empreendimentos sujeitos ao Licenciamento Ambiental as atividades agropecuárias dos projetos de assentamentos rurais e de colonização. A partir daí foi organizada uma Agenda Ambiental INCRA/MDA + IBAMA/MMA em consonância com o Código Florestal para iniciar as discussões acerca dos procedimentos específicos para 0 Licenciamento Ambiental dos Projetos de Assentamentos. Em 1999 o Projeto de Desenvolvimento Sustentável (PDS) foi criado para populações tradicionais ou não, mas que estivessem comprometidas com ouso ecológico dos recursos naturais.

Os anos seguintes foram marcados por revisões nos instrumentos normativos, definição dos procedimentos e instrumentos de licenciamento ambiental dos Projetos de assentamentos de reforma agrária além do repasse de 13 milhões hectares para a criação de Unidades de Conservação e a aprovação do Plano de Gestão Ambiental do INCRA com diretrizes e programas para gestão dos recursos naturais, educação ambiental entre outros.

Em São Paulo, o Projeto de Desenvolvimento Sustentável ${ }^{1}$ (PDS) é incluído no rol de projetos do INCRA a partir de 2010, como alternativa para se evitarem os problemas verificados nos programas tradicionais - evasão e a venda de lotes - que fragilizam a área recém reformada. Esse tipo de projeto pressupõe uma ocupação que organize os lotes individuais na área livre disponível, isso significa que o meio físico existente deverá ser mantido como premissa para instalação das famílias, nesse tipo a produção é coletiva. Essa condição interfere na definição do tamanho das parcelas, por isso nesse tipo de assentamento os lotes de moradia individuais tem aproximadamente um hectare. $\mathrm{O}$ fato da ocupação do PDS ser projetada nas áreas livres de vegetação, e de não devastar a área para implantação dos lotes, há a necessidade de se explorar o desenho de implantação considerando os aspectos

\footnotetext{
${ }^{1}$ Modalidade de projeto criada para o desenvolvimento de atividades ambientalmente diferenciada, destinada às populações que sustentam sua subsistência no extrativismo, na agricultura familiar e em outras atividades de baixo impacto ambiental. A obtenção da terra, a criação do Projeto, a seleção dos beneficiários, o aporte de recursos de crédito Apoio Instalação e de crédito de produção (PROFNAF A) são de responsabilidade da União, assim como infraestrutura básica (estradas de acesso, água e energia elétrica). Nesse tipo de projeto não há individualização das parcelas (Titulação coletiva - fração ideal) e a titulação é de responsabilidade da União. Legislação: Portaria/INCRA/PNo.477, de 4 de novembro de 1999.
} 
ambientais como premissas do ordenamento. É como se fugisse da lógica da divisão de propriedade tradicional que segue um padrão de divisão ortogonal, e sua implantação e desenvolvimento dependem da mobilização das famílias.

A principal diferença entre o PA e o PDS é que, no primeiro, a questão ambiental está considerada nas diretrizes do projeto para a etapa de Licenciamento Ambiental, mas não para o ordenamento dos lotes e definição do uso do solo para projeto de implantação; no segundo, a definição do uso do solo e a produção são definidos a partir da condicionante ambiental da área na qual o projeto será implantado, havendo ainda uma regulamentação específica quanto ao uso de insumos externos e poluentes, como agrotóxicos. Nesse sentido, o PDS implica a prática de uma agricultura ecológica, não se verificando, porém, uma promoção de políticas e créditos diferenciados. Ao que parece, o Governo Federal, nos últimos dez anos, concentrou suas ações na progressão de políticas públicas criadas especificamente para fortalecer o consumo dos produtos dos assentamentos de reforma agrária ${ }^{2}$. No âmbito estadual, ainda que com certa baixa nos quadros técnicos, o ITESP tem, em menor ritmo, acompanhado essa progressão da oferta de políticas para manutenção das famílias assentadas no Estado, mas não tem criado novos projetos e implantações.

As características do meio físico no qual será implantado o assentamento são fundamentais para o projeto de vida que se propõe nesse tipo de ocupação. A topografia, a existência de rios, nascentes e córregos são determinantes não só do traçado, mas também para a definição dos tipos de atividades agrícolas que serão desenvolvidas pelas famílias.

\footnotetext{
${ }^{2}$ Em São Paulo, além do Programa de Aquisição de Alimentos, existem outros dois destinados à aquisição da produção específica dos assentamentos. 0 governo do Estado, via ITESP, mantém o Programa Paulista da Agricultura de Interesse Social (PPAIS), o qual disponibiliza R $\$ 20$ mil/ano/beneficiário, e o Programa Nacional de Alimentação Escolar2 (PNAE) que adquire a produção no valor de até $\mathrm{R} \$ 12 \mathrm{mil} / \mathrm{ano}$.
}

\section{Meio ambiente e o projeto de parcelamento: Zumbi dos Palmares}

Localizado em laras, na região sudoeste do Estado de São Paulo, cercado e recortado por linhas d'água e rios, o projeto de assentamento Zumbi dos Palmares tem sua história relacionada aos projetos de colonização de 1910, quando o Governo Federal comprou terras na região e implantou o Núcleo Colonial Monções, para que imigrantes europeus pudessem viver de sua produção agrícola em lotes individuais. Separado por uma área que havia sido doada ao Governo do Estado de São Paulo, foram parceladas outras duas. A parte sul da ocupação se desenvolveu tornando-se, em 1921, distrito de Santa Bárbara; em 1990 adquiriu autonomia política e administrativa. A parte norte, minguou e aos pouco os lotes foram sendo ocupados por posseiros.

Esquecido pela União, o imóvel foi sendo apossado e loteado por particulares, chegando mesmo a ser dividido em municipalidades e urbanizado. laras é um município resultante dessa fragmentação. Só na década de 1990 a União Federal, através do INCRA, começou a interpor ações judiciais para retomada progressiva de glebas da Fazenda Capivara, imóvel parte do Núcleo original. À medida que a União apresenta títulos que comprovam domínio anterior ao do posseiro atual, a posse é dada ao INCRA e a gleba é incorporada ao PA Zumbi dos Palmares (INCRA, 2012).

O aprofundamento do estudo da forma de parcelamento do Zumbi dos Palmares possibilitou expor os resultados das implantações paulistas, ocorridas entre 19852013, do ponto de vista do projeto de parcelamento para os assentamentos rurais de reforma agrária. A partir das diferenças entre 0 que estava previsto para o projeto e o resultado do ambiente construído, foi possível identificar que, independentemente da esfera na qual o projeto é criado (Federal a Estadual), a forma do parcelamento com a definição do uso do solo e a relação que se propõe com o meio ambiente no qual está inserido dependem da capacidade operacional do órgão responsável pelo projeto e da organização social das famílias. 
Em São Paulo, a estratégia da superintendência do INCRA de descentralizar as operações, criando escritórios e unidades avançadas em regiões que se caracterizam fortemente pela presença dos assentamentos, somado ao Programa Nacional de Assistência Técnica e Extensão Rural, o qual viabilizou a contratação de assistência técnica especializada para atender e orientar as famílias, não foi suficiente para promover até agora um ambiente que não só qualifique, mas que também favoreça 0 desenvolvimento das famílias assentadas.

Em 2008, a iniciativa do INCRA, ao estabelecer o Plano de Gestão Ambiental como instrumento para o desenho dos projetos de assentamento, indica, ainda que institucionalmente, a necessidade de diretrizes com ênfase em aspectos ambientais, uma vez que a maior parte das áreas de reforma agrária representa hoje um passivo ambiental. Esse resultado indica que, na maioria das vezes, o parcelamento da área desconsidera o meio no qual será implantado, dificultando não só o cotidiano, mas também a capitalização das famílias, e implicando a busca de alternativas na geração de renda (políticas públicas especificas para o improviso da inserção dessas famílias no mercado), atrasando o processo de emancipação. No entanto, a participação dos futuros assentados e as dinâmicas ambientais da área são pressupostos da legislação a qual orienta a criação do projeto de assentamento.

A dimensão ambiental, ainda que tenha estado presente nas leis relacionadas ao contexto da reforma agrária, normatizando as atividades de criação e implantação dos assentamentos rurais nem sempre pode ser verificada nas práticas em campo. O contexto emergencial no qual se inscreve a criação do projeto, e o tempo disponível para o desenho de parcelamento, justificam e inviabilizam o cumprimento das etapas previstas para a ocupação da área. $\mathrm{O}$ projeto de ordenamento para novos lotes em mais uma gleba da área do assentamento teve ordem do Ministério Público para que fosse feito com base em critérios técnicos indicando assim que os lotes do Zumbi dos Palmares, implantados até 2013 não tiveram aspectos técnicos considerados e tampouco as condicionantes ambientais da área para definição de tamanho e ordenamento das vias.

A Ordem de Serviço 19 atende à recomendação da Procuradoria da República em Ourinhos, SP, do Ministério Público Federal (MP), que o INCRA proceda ao parcelamento do PA Zumbi dos Palmares servindo-se de critério técnico, uma vez que os parcelamentos das glebas existentes no PA não têm estudo técnico que os justifique (idem).

O documento de 2012, apresentado pelo INCRA como proposta de método de parcelamento da gleba restante no assentamento Zumbi dos Palmares, expõe os objetivos e os princípios técnicos e ambientais considerando as condicionantes socioeconômicas para que o dimensionamento das parcelas permitam o estabelecimento e desenvolvimento de uma família, independentemente de outras formas de renda. A imagem abaixo destaca gleba do assentamento que deverá ter seu ordenamento organizado tendo como base aspectos do suporte físico e critérios técnicos.

Figura 2: Projeto de Assentamento Zumbi dos Palmares com destaque para última gleba a ser ocupada.

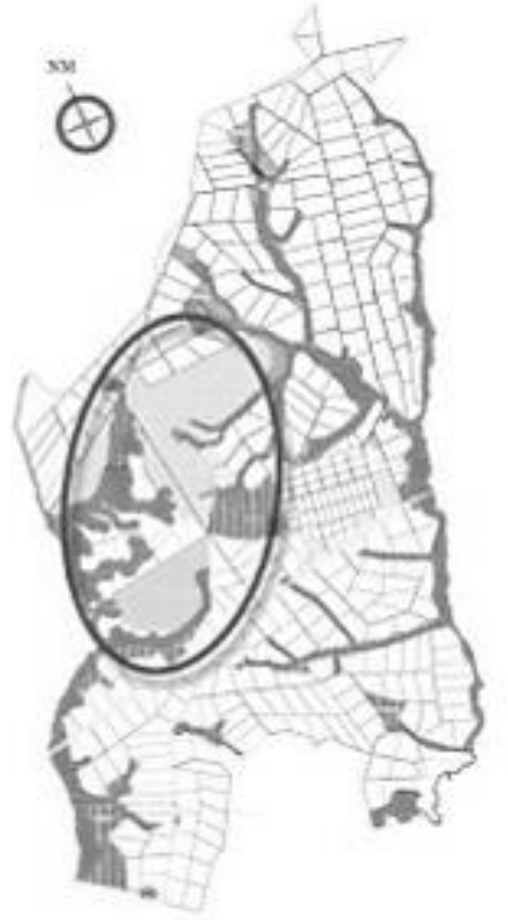

Fonte: INCRA, 2012 
Pela primeira vez, serão considerados aspectos ambientais para a definição de um traçado (vias e lotes) que permita a conservação do solo, dos mananciais e de fragmentos florestais.

Figura 3: Traçado de estradas em relação à topografia do terreno.

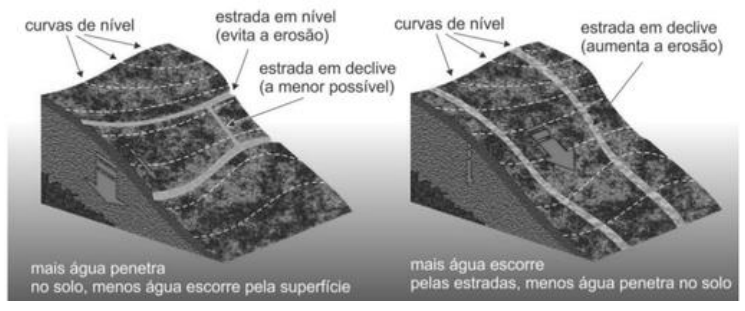

Fonte: INCRA, 2012

A ilustração acima consta no documento representando a relação do traçado com a topografia como parte dos critérios técnicos para ordenamento dos lotes. Analisando-se o processo de criação do assentamento no INCRA não se observam tanto o levantamento topográfico da área quanto considerações a respeito da condicionante hídrica. Os técnicos autores do documento destacam que o lote tem como objetivo ser uma propriedade familiar a qual absorveria a força de trabalho da família para garantir a subsistência, o progresso social e econômico. Indicam que o desenvolvimento rural e a preservação ambiental são indissociáveis (tendo sido assegurado no Estatuto da Terra art. $2^{\circ}$, quando regulamenta o cumprimento da função social da propriedade rural atendendo às condições produtivas, trabalhistas e ambientais).

A problemática ambiental, no Zumbi dos Palmares, teve origem na fase do acampamento e impactou a vida das famílias que vivem lá hoje. É um dos principais aspectos que caracterizam a precariedade do ambiente construído no assentamento, uma vez que as águas dos rios que delimitam a área ocupada foram contaminadas devido à falta de esgotamento sanitário adequado na fase de acampamento e pós-ocupação. Constituído em 20 de novembro de 1995, centenário de morte de Zumbi dos Palmares, o acampamento foi organizado por cerca de 60 famílias, vindas de diversas regiões do Estado de São Paulo.
Organizadas pelo Movimento dos Trabalhadores Rurais Sem Terra (MST), ocuparam 2.400 hectares da Fazenda Capivara. Os trabalhadores acamparam na área usada pelo Instituto Florestal, cedida conforme determinação do Governo Federal. Este foi o primeiro passo para que as terras públicas da região fossem objetos da Reforma Agrária (SOUZA, 2007).

Tabela 1: Número de lotes criados por ano no assentamento Zumbi dos Palmares.

\begin{tabular}{ll}
\hline Ano & $\begin{array}{l}\text { No Unidades Agrícolas } \\
\text { Criadas }\end{array}$ \\
\hline 1998 & 54 \\
2003 & 172 \\
2005 & 9 \\
2008 & 136 \\
2012 & 6 \\
TOTAL - 2013 & $\mathbf{3 7 7}$ \\
\hline
\end{tabular}

A tabela 1 indica os anos e o número de lotes criadas no AZUP. Analisando 0 arquivo do processo de criação e o anteprojeto de parcelamento dos lotes, em nenhum momento verificou-se, como afirmam os técnicos, na proposta de metodologia para parcelamento de gleba, que não há, para as implantações anteriores, estudos que justifiquem o traçado e a definição do tamanho dos lotes.

A maior parte das parcelas de Zumbi foi delineada dentro da faixa de 12 a 20 ha, com traçado quadricular. Os motivos que levaram a essa escolha não são claros para esta equipe, exceto que atenderam à urgência do assentamento das famílias acampadas nas proximidades ou nos próprios imóveis (INCRA, 2012).

Analisando-se $o$ parcelamento ano a ano observa-se certa diminuição do tamanho da área do lote. Somando as informações do documento tomado como referência e o levantamento de campo realizado em 2013 foi possível identificar ao menos quatro formas principais de ocupação produtiva nos lotes: culturas olerícolas; pastagens de baixa produtividade; florestas plantadas para extração de madeira e resina; áreas ociosas.

Nas imagens da figura 4 apresentam-se as 
áreas ocupadas a cada ano de implantação com identificação do uso do solo, das áreas verdes e dos rios que delimitam 0 assentamento. Nota-se que a partir de 2003 são demarcadas as áreas de Preservação Permanente (APP) nas margens dos rios e córregos e área que deveria ser destinada à parte de Reserva Legal (RL) para o cumprimento da legislação vigente. As áreas foram delimitadas em projeto, mas não foram reconhecidas em campo e por isso não houve emissão do Licenciamento Ambiental, implicando importante gargalo na evolução econômica e social das famílias. A ausência desse documento inviabiliza 0 acesso das associações e cooperativas de assentados aos recursos disponíveis nos programas, por exemplo, aqueles de aquisição de alimentos. $A$ demarcação em projeto é decorrente do laudo para identificação do passivo ambiental documentado em 2001. Destaca-se aqui que a área de $\mathrm{RL}$ representada é na verdade uma plantação de Pinus e que foi utilizada no decorrer dos anos para aumento da capacidade do PA.
Figura 4: Destaque para localização de cada etapa de implantação.

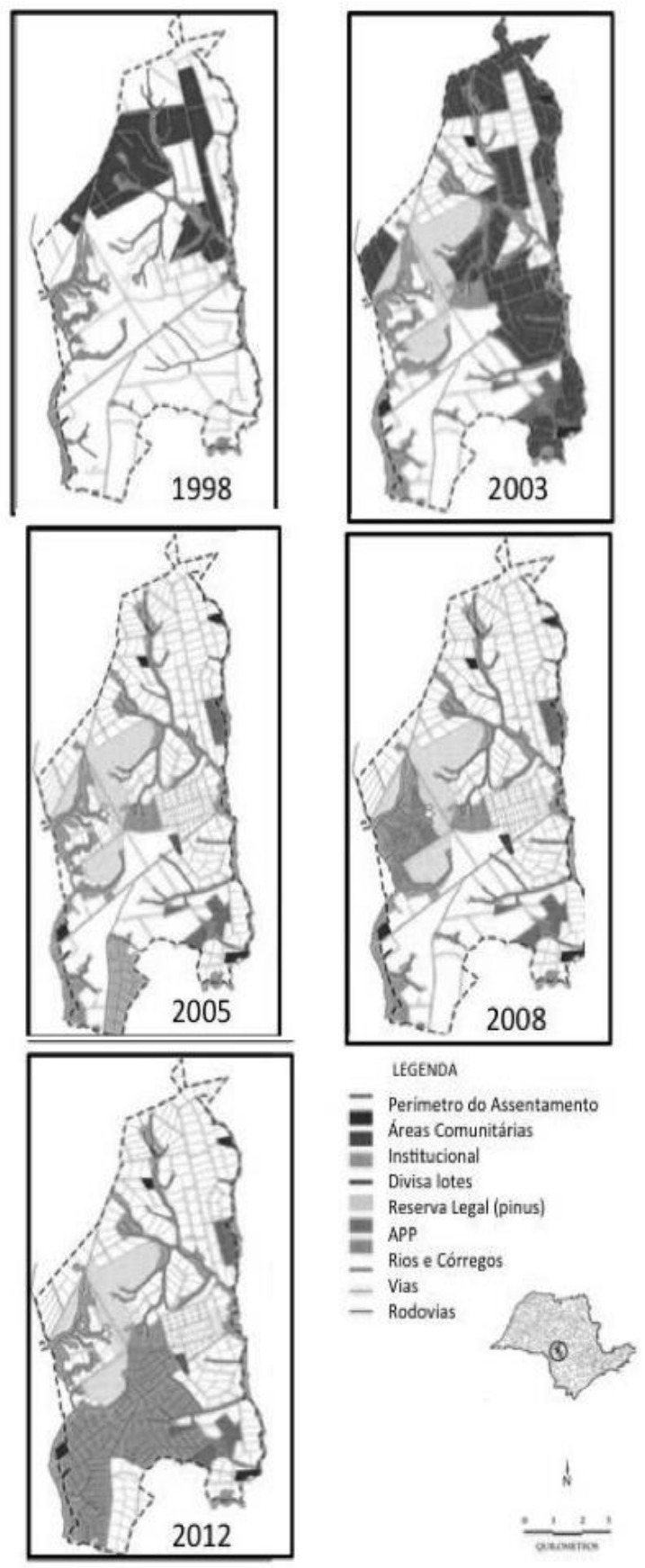

As figuras 4 e 5 foram elaboradas durante as pesquisas para a dissertação de mestrado. São composições feitas a partir do projeto de parcelamento contido no processo de criação do assentamento (INCRA) associado às imagens de satélite (Google Earth) da ocupação do assentamento dos anos 2001, 2008, 2011, 1015. O que se observa é uma diminuição das áreas de Reserva Legal nos anos nos quais se registram a inclusão de novos beneficiários, 
improvisando um aumento na capacidade do assentamento. As áreas de preservação permanente que corresponde à margem dos rios e córregos estão definidas em projeto, porém em campo, o que se verifica é que algumas famílias não o fizeram, e a justificativa tem sido o fato de não conseguirem administrar os recursos disponibilizados. Considerou-se para análise as delimitações das áreas verdes estabelecidas em projeto projetadas sobre imagem de satélite (manchas verdes).

Figura 5: Evolução da ocupação do assentamento Imagem Google Earth (2001 - 2014).

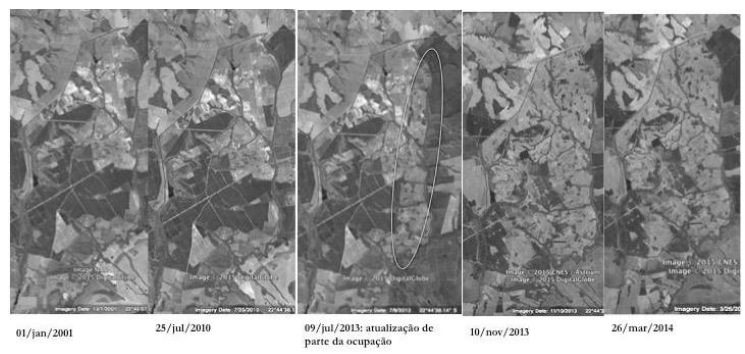

Fonte: Elaboração própria, 2013

Registrada em levantamento de campo de 2013, a figura 6, corresponde a área ocupada em 2012. O parcelamento dos novos lotes foi feito em uma gleba que estava indicada em projeto (2008) como área de reserva. O assentamento foi criado em uma área que está cercada por outras glebas que podem tornar-se parte do assentamento, pois faziam parte do conjunto de fazendas do Núcleo Colonial Monções, a cada nova conquista de obtenção e reconhecimento nos lotes eram demarcados fazendo desaparecer quase toda a área definida em projeto como de Reserva Legal. Em visita ao assentamento foi possível registrar que essas áreas são formadas majoritariamente por plantações de pinus.

No âmbito do projeto percebe-se que a metodologia de parcelamento dos lotes não considera a interface entre as condicionantes ambientais, o tamanho da área e as dinâmicas específicas que abarcam os cotidianos das famílias assistidas, o que resulta em maiores dificuldades para a fixação das famílias como assentados de reforma agrária.
Figura 6: Lote implantado em 2012 em área aberta em meio à plantação de eucalipto - aumento da capacidade do assentamento.

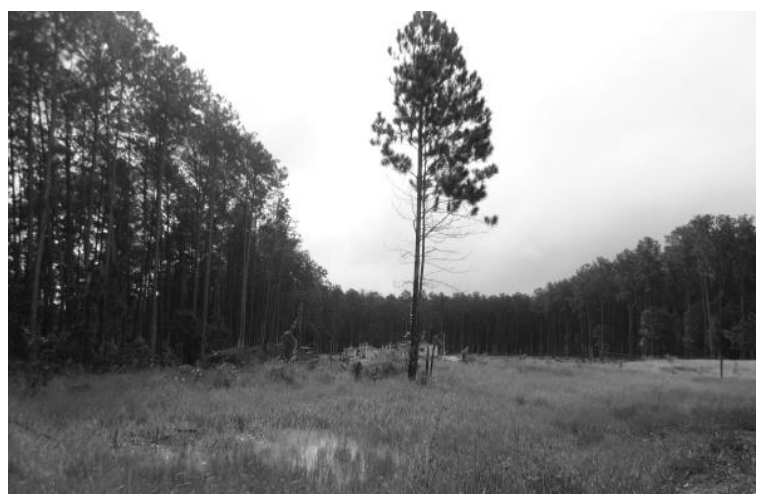

A diminuição dessas áreas em função do aumento do aumento da capacidade do assentamento faz com que os requisitos necessários para obtenção do Licenciamento Ambiental não sejam cumpridos implicam dificuldades que forçam os assentados a migrar para o trabalho na produção sucroalcooleira das fazendas vizinhas.

O saneamento básico no assentamento, influente direto da qualidade ambiental das águas e da terra, ainda que abordado nas diretrizes de projeto, não aparece na implantação dos lotes. As fossas sépticas ou biodigestoras parecem na prática com a operação do programa piloto para a aquisição de material para reforma ou construção das unidades habitacionais. Sem levar em consideração a organização social das famílias e a localização de cada lote os grupos de mutirão foram organizados por ordem de entrega da documentação e demorou mais de seis anos para ser concluído, deixando de cumprir metas e expectativas. Durante os primeiros dez anos de implantações a fossa negra (esgotos conectados a um buraco no chão sem tratamento) foi o sistema sanitário mais adotado e o abastecimento de água a partir de poços. A partir dos anos 2007 cerca de cinquenta lotes do AZUP adquiriram, como sistema de tratamento hidro-sanitário, fossas biodigestoras, oferecidas pela EMBRAPA ${ }^{3}$. Outros dez lotes construíram suas fossas com tubos de concreto, conforme projeto oferecido e

\footnotetext{
${ }_{3}^{3}$ Empresa Brasileira de Pesquisa Agropecuária
} 
demonstrado pela equipe de moradia em 2008.

\section{Considerações}

A consequência de um anteprojeto de parcelamento, elaborado sem critérios técnicos e sem consideração com o suporte natural, ainda que previstos nos procedimentos legais para elaboração do projeto de assentamento, é um ambiente construído comprometido do ponto de vista ambiental e frágil do ponto de vista social. Destaca-se que já no Estatuto da Terra (1964) desenha-se a contradição entre o meio ambiente e a expectativa de resultados econômicos com a produção no lote de um assentamento rural. A Lei prevê, de forma contraditória, por um lado, atividades de assistência técnica para racionalização do solo, a execução de planos de reflorestamento, e a defesa e preservação dos recursos naturais ${ }^{4}$; e, de outro, apoia o financiamento para compra de insumos que prejudicam o meio ambiente ${ }^{5}$. A implantação do assentamento, como se viu, não necessariamente é feita de maneira apropriada para instalação de famílias que viverão da produção rural. Os técnicos, ao definir a forma de uso e ocupação da área, consideram a reprodução de um padrão de parcelamento a partir do módulo que define o tamanho do lote, mas não tomam para o projeto, parâmetros que considerem as pessoas que ali irão viver.

Não há, no processo de criação do Assentamento Zumbi dos Palmares, uma planta de levantamento topográfico que indique as massas de vegetação existente. Pela análise das imagens de satélite, percebe-se que há uma diminuição, ao longo do tempo, das massas verdes que deram lugar a novos lotes, ampliando a capacidade do assentamento e diminuindo as áreas destinadas à reserva ambiental. O fato de não ter sido considerado o suporte físico gerou uma condição de infraestrutura frágil impactando o cotidiano das famílias. O remanescente das áreas de preservação e reserva ambiental é esparso, mínimos em algumas parcelas e inexistente em outras. $O$ assentamento aparece nas imagens

${ }^{4}$ Art. 75, parágrafo 4o, alínea e

${ }^{5}$ Art. 86, inciso II de satélite a partir de 2001. A imagem de 2013 atualiza uma parte da ocupação do Zumbi dos Palmares, deixando clara a interferência no ambiente natural.

Ainda que o INCRA tenha investido nos últimos anos em assistência técnica mais especializada ${ }^{6}$, e esta ser vetor importante para - aumento da prática agrícola com menor interferência ambiental - adequada à produção da agricultura familiar - não tem legitimado sua capacidade de fiscalizar a condição ambiental da ocupação.

O descompasso entre o tempo político e o tempo social parece favorecer a fragilidade ambiental. A existência de legislação específica e a problemática que se verifica na resultante construída representam mais de quinze anos de ocupação assim como indicam que há avanço na elaboração de leis que regulamentam a dimensão ambiental no âmbito da reforma agrária, mas falta compatibilidade com a prática. Existe um abismo entre o meio ambiente resultante do projeto de assentamento e aquilo que está previsto na legislação e nas diretrizes. Por isso, considera-se que identificação das condicionantes ambientais existentes devem ser os parâmetros inicias do projeto de parcelamento.

Por fim, ainda que a vegetação existente não seja favorável à produção, como no caso do pinus/eucalipto existente nas áreas do Zumbi, poderiam ter sido consideradas, ao menos para organização das divisas dos lotes, ou na beira das estradas para gerar sombreamento no caminho de pedestres uma vez que a maioria das famílias residentes não tem carro.

\section{Referências}

AMARAL, D.T., BOTTA, Vera Lúcia S. Ferrante. Dimensão ambiental em assentamentos rurais: presença controversa. Retrato de Assentamentos, Araraquara, v.15, n.2, p.179-

\footnotetext{
- A política de assistência técnica e extensão rural (PNATER, 2007) teve o Manual Operacional ATES/INCRA publicado em 2008 no qual ressalta o papel educativo da assistência técnica em promover a formação e capacitação das famílias assistidas priorizando práticas sustentáveis e ecológica. (p. 198).
} 
203, 2012.

Instituto Brasileiro de Geografia e Estatística (IBGE): http://www.ibge.gov.br (acessado em janeiro de 2015).

INCRA - Instituto de Colonização e Reforma Agrária. Terras públicas do Núcleo Colonial Monção serão transferidas ao Incra/SP. 2011. 09 mai. 2011. Disponível em: $<$ http://www.incra.gov.br/index.php/noticias-salade-imprensa/noticias/1266-terras-publicas-donucleo-colonial-moncao-serao-transferidas-aoincrasp>.Acesso em: 18 mai. 2012.

. Proposta de método de parcelamento de uma Gleba do Assentamento Zumbi dos Palmares, laras, SP. 2012. Disponível em: $<$ http://pt.slideshare.net/incranian/propostaparcelamento-zumbi-iaras-os-192012>. Acesso em 20 jan. 2015

Plano de Ação Ambiental do INCRA. http://www.incra.gov.br/sites/default/files/plano_ acao_ambiental_v11dez2008.pdf

MITIDIERO JUNIOR, M. A. Reforma Agrária No Brasil: Algumas Contribuições Sobre A Materialização Dos Assentamentos Rurais. Agrária, São Paulo, n.14, p.4-22, 2011. Disponível em: <http://www.revistas.usp.br/agraria/article/view/5 5794/59203> Acesso em: 14 set. 2012.

SILVA, Ligia Teresa Paludetto. Uma visão ambiental da gênese dos assentamentos rurais no estado de São Paulo: de Sumaré ao Pontal do Paranapanema. 2006, s/p. Dissertação (Mestrado em Arquitetura e Urbanismo) Faculdade de Arquitetura e Urbanismo da Universidade de São Paulo, São Paulo, 2006.

SOUZA, F. S. et. al. Impacto socioeconômico da reforma agrária no município de laras. Monografia (Bacharelado em Geografia) Faculdade Sudoeste Paulista, 2007. 